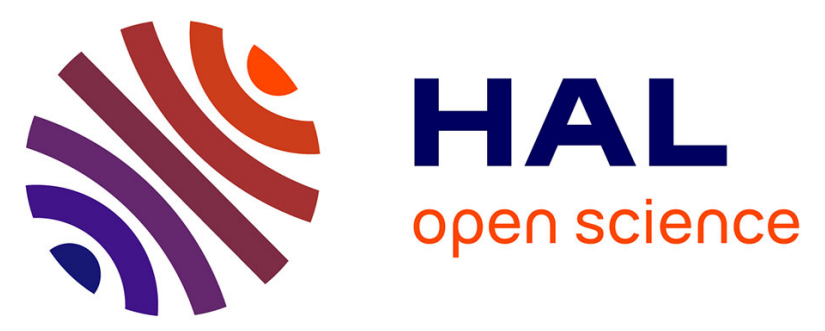

\title{
Experimental characterization of post rigor mortis human muscle subjected to small tensile strains and application of a simple hyper-viscoelastic model
} Laure-Lise Gras, Sébastien Laporte, Philippe Viot, David Mitton

\section{- To cite this version:}

Laure-Lise Gras, Sébastien Laporte, Philippe Viot, David Mitton. Experimental characterization of post rigor mortis human muscle subjected to small tensile strains and application of a simple hyper-viscoelastic model. Proceedings of the Institution of Mechanical Engineers. Part H, Journal of engineering in medicine, 2014, 228 (10), pp.1059-1068. 10.1177/0954411914555422 . hal-01214125

\author{
HAL Id: hal-01214125 \\ https://hal.science/hal-01214125
}

Submitted on 17 Sep 2021

HAL is a multi-disciplinary open access archive for the deposit and dissemination of scientific research documents, whether they are published or not. The documents may come from teaching and research institutions in France or abroad, or from public or private research centers.
L'archive ouverte pluridisciplinaire HAL, est destinée au dépôt et à la diffusion de documents scientifiques de niveau recherche, publiés ou non, émanant des établissements d'enseignement et de recherche français ou étrangers, des laboratoires publics ou privés. 


\title{
Experimental characterization of post rigor mortis human muscle subjected to small tensile strains and application of a simple hyper-viscoelastic model
}

\author{
Laure-Lise Gras' ${ }^{1,2,3,4}$, S 'e bastien Laporte', Philippe Viot ${ }^{5}$ and David Mitton 2,3,4
}

\begin{abstract}
In models developed for impact biomechanics, muscles are usually represented with one-dimensional elements having active and passive properties. The passive properties of muscles are most often obtained from experiments performed on animal muscles, because limited data on human muscle are available. The aim of this study is thus to characterize the passive response of a human muscle in tension. Tensile tests at different strain rates $\left(0.0045,0.045\right.$, and $\left.0.45 \mathrm{~s}^{-1}\right)$ were performed on 10 extensor carpi ulnaris muscles. A model composed of a nonlinear element defined with an exponential law in parallel with one or two Maxwell elements and considering basic geometrical features was proposed. The experimental results were used to identify the parameters of the model. The results for the first- and second-order model were similar. For the first-order model, the mean parameters of the exponential law are as follows: Young's modulus $E$ $(6.8 \mathrm{MPa})$ and curvature parameter $\alpha(3 \mathrm{l} .6)$. The Maxwell element mean values are as follows: viscosity parameter $\eta$ ( $1.2 \mathrm{MPa}$ ) and relaxation time $\tau(0.25 \mathrm{~s})$. Our results provide new data on a human muscle tested in vitro and a simple model with basic geometrical features that represent its behavior in tension under three different strain rates. This approach could be used to assess the behavior of other human muscles.
\end{abstract}

\author{
Keywords \\ Biomechanics, human muscle, strain rate, tensile test, Maxwell model
}

\section{Introduction}

Different muscle models have been developed in the impact biomechanics field. Some are finite element models with constitutive laws defined to describe both the passive and active responses of the muscles in three dimensions. ${ }^{1-4}$ For instance, Behr et al. ${ }^{1}$ proposed a finite element model of a muscle that takes into account the effect of muscle's fibers. However, even though the trend is to implement three-dimensional (3D) finite element models, muscles are still often described in most of the human body models as one-dimensional (1D) elements with specific properties. ${ }^{5-11}$ The muscles are usually modeled with Hill's model. This model has passive and active properties, and its passive mechanical properties are obtained from experiments on animal muscles and implemented in the human body models.

The passive response of muscles has been widely studied with experiments performed on muscle in compression $^{12-19}$ or tension. ${ }^{20-29}$ However, most of these experiments have been performed on animal muscles. Very few experiments have been conducted on human muscles in vitro in compression ${ }^{14,30,31}$ and tension. ${ }^{32-34}$ Even if animal data are considered for human body models, high variability is noted in the

\footnotetext{
'Laboratoire de Biomécanique (LBM), Arts et Metiers ParisTech, Paris, France

${ }^{2}$ Université de Lyon, F-69622, Lyon, France

${ }^{3}$ Université Claude Bernard Lyon I, Villeurbanne, France

${ }^{4}$ IFSTTAR, UMR_T9406, LBMC Laboratoire de Biomécanique et

Mécanique des Chocs, F-69675, Bron, France

${ }^{5}$ Arts et Metiers ParisTech, I2M-DuMAS, UMR 5295 CNRS, Talence,

France
}

Corresponding author:

Laure-Lise Gras, Département de Mécanique, Université Claude Bernard Lyon I, Bât. Omega, 43 Bd du II novembre, 69622 Villeurbanne, France. Email: laurelise.gras@gmail.com 
experimental results presented in the literature. For instance, at the fiber level, Mutungi and Ranatunga ${ }^{35}$ found a Young's modulus of around $1 \mathrm{MPa}$ for slow fibers and around $0.1 \mathrm{MPa}$ for fast fibers of rats' muscles, while Lieber et al. ${ }^{36}$ evaluated a Young's modulus of $462.5 \mathrm{MPa}$ for human muscle fibers. These results suggest that differences between human and animal muscle tissue exist. Therefore, it seems relevant to study human muscle tissue in vitro, even though such studies imply limitations such as testing fairly old and not fresh tissue.

Moreover, muscle mechanical properties differ from one muscle to another in a same subject. ${ }^{34,37}$ Indeed, Best et al. ${ }^{37}$ who studied two different muscles of the rabbit leg found a stress at $10 \%$ strain for the tibialis anterior that was $35 \%$ of the stress at the same strain level for the extensor digitorum longus. Even though results were normalized with global parameters common to both muscles, they show the difficulty in comparing data that depend on the muscle and also on the applied experimental conditions. These differences may be related to muscles' geometry, fiber composition, extracellular matrix (collagen), and so on. In order to identify which characteristic is more prevalent on muscle response, a first step would be to characterize different muscles and thus create a database of muscle mechanical properties.

Our group recently showed that the hyper-elastic tensile behavior of the human sternocleidomastoideus muscle can be described using a simple model (exponential) considering basic geometrical features (initial length and cross-sectional area). ${ }^{32}$ In addition to the hyper-elastic behavior, viscosity parameters have been added through a first- or second-order Maxwell model. $^{33}$ The parameters were identified using an inverse finite element method and a quasi-static tensile test followed by a load-relaxation test. The secondorder model was more prone to characterize the viscoelastic response of the sternocleidomastoideus, but the first-order model still gave a good estimate of the muscle response.

These results were obtained for a specific muscle, age group, gender, and experimental protocol. In order to extend our knowledge on human muscle hyperviscoelastic mechanical properties, the aim of this article was thus to evaluate the ability of the same simple hyper-viscoelastic model to characterize the response of another human muscle subjected to a different in vitro experimental protocol including various velocities.

\section{Materials and methods}

\section{Muscle specimens}

Ten extensor carpi ulnaris muscles were collected from the right and left forearms of five male subjects (mean age: 71.6 years) that were frozen 4 days after their death, that is, post rigor mortis, and slowly thawed at
$4{ }^{\circ} \mathrm{C}$ before muscles were removed from the body. This specific muscle was considered because it is superficial and easily accessible. It is a pinnate muscle. The muscles were removed with their aponeurosis, tendons, and two ends of bone blocks. They were wrapped in gauzes soaked with physiological saline solution, vacuumpacked, and frozen at $-20^{\circ} \mathrm{C}$. The muscles were slowly thawed for $12 \mathrm{~h}$ at $4{ }^{\circ} \mathrm{C}$ and then stored for $2 \mathrm{~h}$ at ambient temperature until the tests were conducted.

\section{Tensile tests}

The muscle extremities were casted in jaws with an epoxy resin (exothermic temperature below $50{ }^{\circ} \mathrm{C}$ ) (Figure 1). The osseous proximal extremity of the muscle was encapsulated in the jaw. The distal extremity presented a large tendon. To limit its effect on the muscle's response, it was set in the resin. The muscle was placed vertically between the jaws, and care was taken to avoid muscle twisting. The set of the muscle and jaws was then placed on a servo-hydraulic testing machine (INSTRON $^{\circledR}$ 8802, High Wycombe, UK) controlled in displacement.

After positioning, the muscle was in a slack state that corresponded to a no-load position, and then the muscle was elongated until a $5 \mathrm{~N}$ pre-load was reached. This load corresponded to $5 \%$ of the expected load at failure of the muscle that was determined from a series of preliminary tests conducted up to failure on the extensor carpi ulnaris muscle of three other human subjects. Then, cyclic tensile tests were applied to the muscle to reach a steady state (50 triangular cycles, total amplitude: $2 \mathrm{~mm}$, frequency: $0.5 \mathrm{~Hz}$ ). This preconditioning phase was close to the experimental protocol proposed by Best et al., ${ }^{37}$ Myers et al., ${ }^{26}$ and Noonan et al. ${ }^{27}$ who preconditioned a tibialis anterior muscle of rabbit by applying $6 \mathrm{~mm}$ displacement $(5 \%$ of the load at failure), $1 \mathrm{~Hz}$ haversine for 50 cycles. Moreover, Van Ee et al. ${ }^{38}$ have shown that for muscles that were previously frozen, up to 50 cycles were required to have a mechanical stabilization of the load (less than $2 \%$ variation), and that this stabilization induced a more reproducible response of the muscle.

At the end of the pre-conditioning phase, the length $l(\mathrm{~mm})$ and cross-sectional area $S\left(\mathrm{~mm}^{2}\right)$ of the muscle were defined. Afterward, stretch ramps of $8 \mathrm{~mm}$ displacement were applied to the muscle. Each muscle was tested at three velocities: 1,10 , and $100 \mathrm{~mm} \mathrm{~s}^{-1}$. The ramps at 1 and $10 \mathrm{~mm} \mathrm{~s}^{-1}$ were applied in a random order, and then the test at $100 \mathrm{~mm} \mathrm{~s}^{-1}$ was conducted. Owing to high-speed grips, constant speeds were imposed to the muscle during the whole tension phase. After each ramp test, the sample was released back to post-stabilization length at the same velocity. Between each test, a rest period of at least 5 min was maintained. A visual inspection of the muscle between each test ensured that tissue was not damaged at the macroscopic level. Displacement $d(\mathrm{~mm})$ was measured with a linear variable differential transformer (LVDT) sensor 


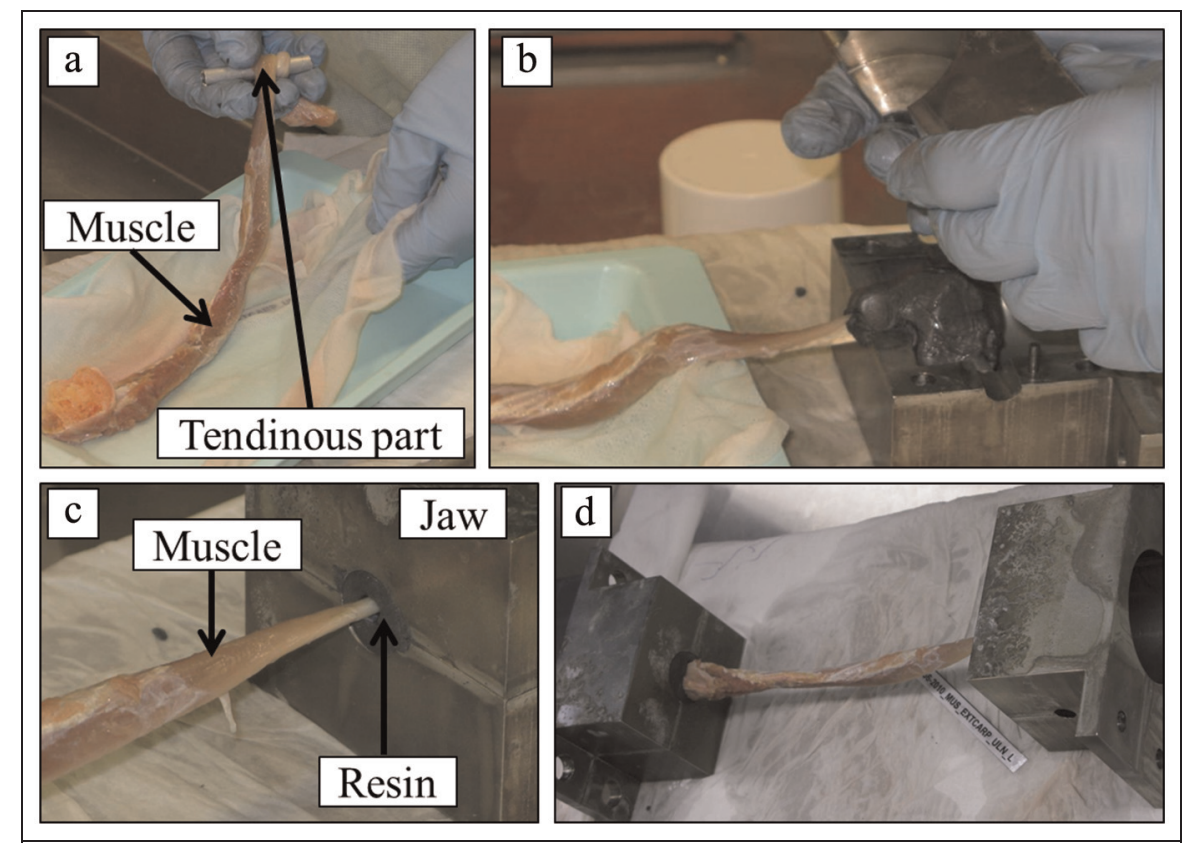

Figure I. Protocol to place muscle in the jaws: (a) the muscle tendinous part is rolled around a screw, (b) muscle is placed in jaws and its extremity is casted with epoxy resin, (c) extremities are casted with epoxy resin, and (d) final result.

(accuracy of $1 \%$ ), and load $F(\mathrm{~N})$ with a $1-\mathrm{kN}$ sensor (accuracy of $0.5 \%$ ). Over the 30 -min duration of the test, the muscle was regularly moistened with physiological saline solution to avoid dehydration. No sliding of the specimen was observed during the experiments.

\section{Muscle's geometrical parameters}

Muscle's initial length $l$ and initial cross-sectional area $S$ were determined using two cameras placed in front of the muscle (Figure 2). Each camera gave one image of the muscle. The length $l$ was measured on each image after the pre-load. Then, at the middle length of the muscle, the width $W$ was measured (Figures 2 and 3) from the same images. This parameter was used to calculate the cross-sectional area of the muscle. This area is assumed to be an ellipse

$$
S=\pi a b
$$

This assumption is based on a series of preliminary tests where muscles were scanned and whose cross section in the middle was approached by an ellipse. There was $1.8 \%$ error between the real area of the muscle and the area estimated with the ellipse.

The ellipse's parametric equation in the global reference space is

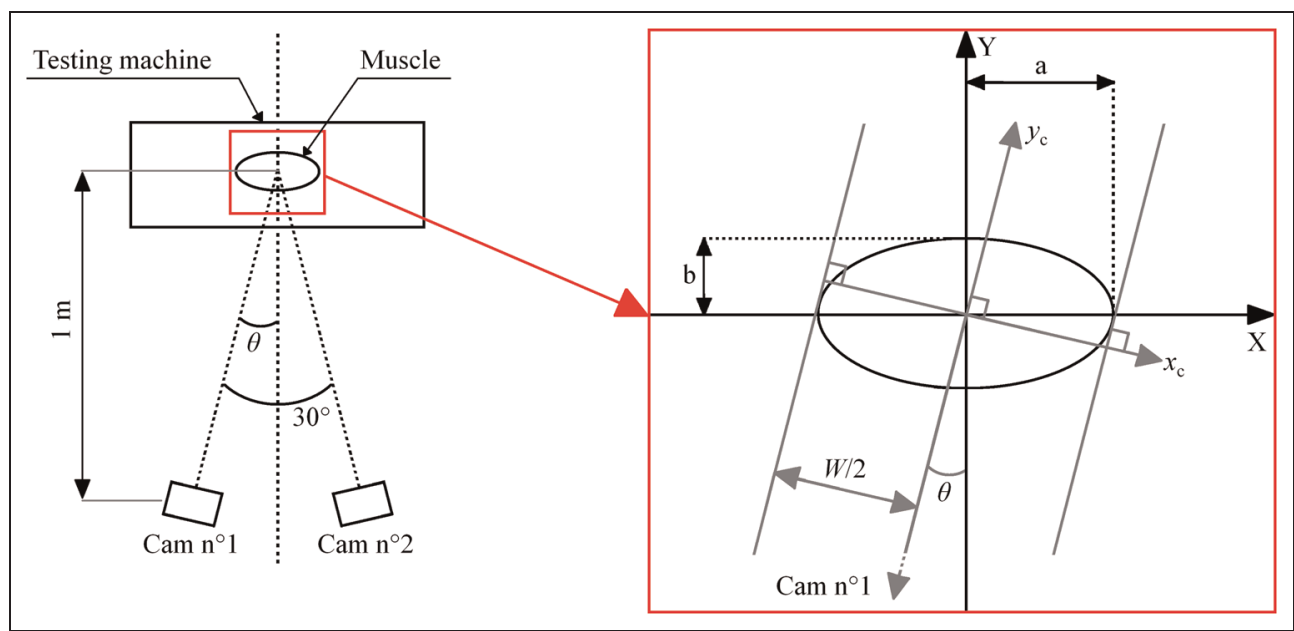

Figure 2. Top view of the position of the muscle on the testing machine and of the cameras in front of the muscle (distance and orientation angle $\theta$ ), and definition of the coordinate systems $\left(X Y\right.$, and $\left.x_{c} y_{c}\right)$, length measured on the picture provided by the camera $(\mathrm{W})$, and the parameters of the ellipsoid $(a$ and $b)$. 


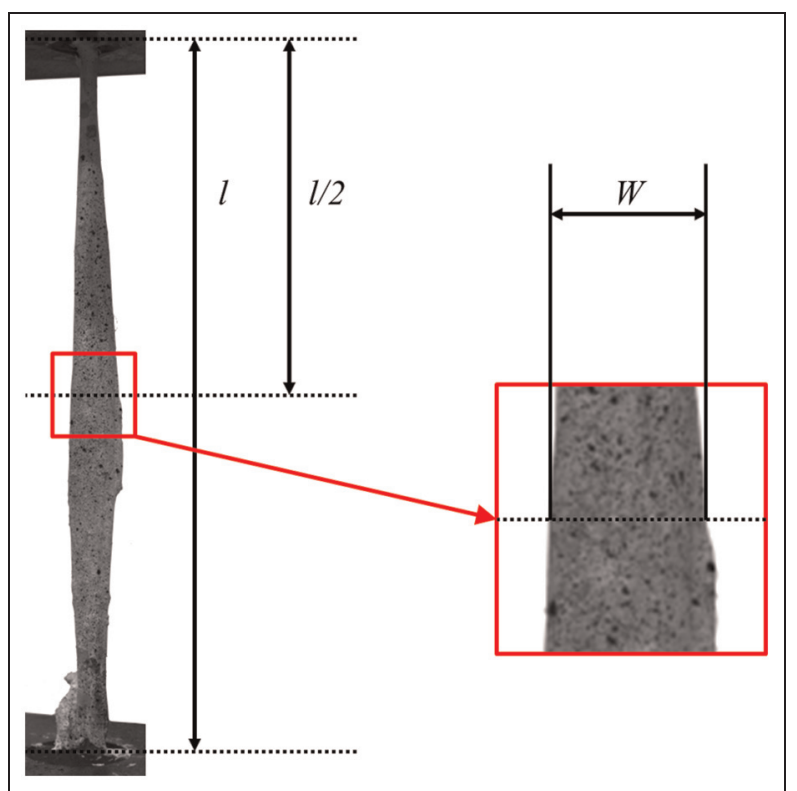

Figure 3. Measurements of the different lengths I and W obtained from the camera images. First, $l$ is measured, and then at middle length, $W$ is measured in pixels. These measurements are used to define the engineering strain and stress applied to each muscle.

$$
X=a \cos (t) ; \quad Y=b \sin (t)
$$

In the reference space of one camera, the projection along the abscissa is

$$
x_{c}=a \cos (t) \cos (\theta)+b \sin (t) \sin (\theta)
$$

with $\theta$ the inclination angle of the camera $\left(15^{\circ}\right)$. As a consequence, $W$ is the length obtained when $x_{c}$ is maximum, that is, when $\tan (t)=(b / a) \tan (\theta)$, and its expression is

$$
\frac{W}{2}=\left[a^{2} \cos ^{2}(\theta)+b^{2} \sin ^{2}(\theta)\right]^{1 / 2}
$$

The two images obtained from the cameras gave two measures of $W$, and with a nonlinear mean squares method, the parameters $a$ and $b$ were identified, and thus $S$. The cost function was

$$
\begin{aligned}
f= & (1 / 2)^{2}\left[W_{\text {Cam no.1 }}-W_{\text {Theory }}\right]^{2} \\
& +(1 / 2)^{2}\left[W_{\text {Cam no.2 }}-W_{\text {Theory }}\right]^{2}
\end{aligned}
$$

The conversion coefficients from pixel to meters were calculated using a reference length on the image. The method was validated using a cylinder of $200 \mathrm{~mm}$ length and $30 \mathrm{~mm}$ diameter. The mean error was $3.5 \%$. For each muscle, the method was reproduced three times in a random order. The reproducibility error was less than $3 \%$. The values chosen for $l$ and $S$ were the mean values of these three measurements. These parameters were used to obtain the engineering stress $\sigma_{\text {experiment }}=F / S$ $(\mathrm{Pa})$ and strain $\varepsilon_{\text {experiment }}=d / l$ of the muscle's response.

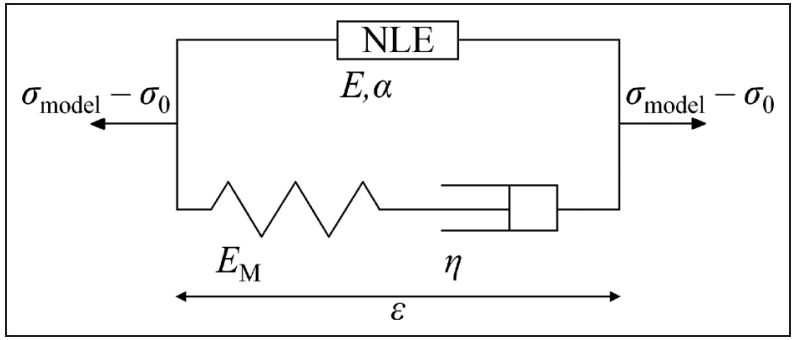

Figure 4. Nonlinear viscoelastic model. The nonlinear element is defined with parameters $E$ and $\alpha$. The Maxwell element is defined with parameters $E_{M}$ and $\eta$.

\section{Statistical analysis}

To assess the influence of velocity on muscle response, a statistical test was used on the maximum stress obtained from the experimental curves. The null hypothesis expressed the fact that velocity had no significant influence on the maximum stress. A risk of $5 \%$ was considered. As the number of tested muscles was small, and the results were paired, the Wilcoxon signed rank test for paired samples was used.

\section{Nonlinear viscoelastic model}

A nonlinear viscoelastic model was chosen to characterize the engineering stress-engineering strain of each muscle. This model is composed of a nonlinear element in parallel with one (first-order model) or two (secondorder model) Maxwell elements (Figure 4). The nonlinear element response is defined by an exponential law as proposed by Sten-Knudsen ${ }^{39}$

$$
\sigma_{N L}=\frac{E}{\alpha}\left[\exp \left(\alpha \varepsilon_{\text {experiment }}\right)-1\right]
$$

where $\sigma_{N L}$ is the stress for the nonlinear element $(\mathrm{Pa})$, $\varepsilon_{\text {experiment }}$ is the strain $\left(\varepsilon_{\text {experiment }}=d / l\right), E$ is a Young's modulus $(\mathrm{Pa})$, and $\alpha$ is a curvature parameter (dimensionless).

The stress $\sigma_{M}(\mathrm{~Pa})$ in the Maxwell elements in tension is described as

$$
\sigma_{M}=\sum_{i=1}^{n} \eta_{i} \dot{\varepsilon}_{0}\left[1-\exp \left(\frac{-t}{\tau_{i}}\right)\right]
$$

where $t$ is the time $(\mathrm{s}), \dot{\varepsilon}_{0}$ is the constant applied strain rate depending on each muscle initial length, $\tau_{i}$ is the relaxation time (s), $\eta_{i}$ is the viscosity ( $\mathrm{Pa} \mathrm{s}$ ), and $n$ is the number of Maxwell elements used in the model. The equivalent Young's modulus for this element is $E_{M}=\sum_{i=1}^{n} \eta_{i} / \tau_{i}(\mathrm{~Pa})$. The global stress can be written as

$$
\sigma_{\text {model }}-\sigma_{0}=\sigma_{N L}+\sigma_{M}
$$

where $\sigma_{0}(\mathrm{~Pa})$ is the experimental stress just after the pre-load. The parameters of the model that have to be identified are $E, \alpha, \eta_{i}$, and $\tau_{i}$. These parameters were identified using MATLAB $^{\circledR}$ R2008b software with a 
nonlinear least-square method (function 1sqnonlin, with the trust-region-reflective method); the cost function was

$$
\begin{aligned}
f= & \frac{1}{n_{1}}\left[\sigma_{\text {experiment }}\left(v_{1}\right)-\sigma_{\text {model }}\left(v_{1}\right)\right]^{2}+\frac{1}{n_{10}} \\
& {\left[\sigma_{\text {experiment }}\left(v_{10}\right)-\sigma_{\text {model }}\left(v_{10}\right)\right]^{2} } \\
& +\frac{1}{n_{100}}\left[\sigma_{\text {experiment }}\left(v_{100}\right)-\sigma_{\text {model }}\left(v_{100}\right)\right]^{2}
\end{aligned}
$$

where $\sigma_{\text {experiment }}\left(v_{1}\right)$ is the experimental stress at $1 \mathrm{~mm} \mathrm{~s}^{-1}$, and $\sigma_{\text {model }}\left(v_{1}\right)$ is the stress obtained according to equation (8) at $1 \mathrm{~mm} \mathrm{~s}^{-1}$. The terms $v_{10}$ and $v_{100}$ refer to the 10 and $100 \mathrm{~mm} \mathrm{~s}^{-1}$ velocities, respectively, and $n_{1}, n_{10}$, and $n_{100}$ refer to the numbers of experimental points for each tensile test at each respective velocity. Therefore, the identified parameters depend on each muscle geometrical characteristics and applied strain rates. During optimization, initial parameters were necessary. They were the same for all the tested muscles and for both the first- and second-order models: $E_{\text {init }}=10 \mathrm{MPa}, \quad \alpha_{\text {init }}=50, \quad \eta_{i} \quad$ init $=0.5 \mathrm{MPas}, \quad$ and $\tau_{i \text { init }}=0.2 \mathrm{~s}$. The identified parameters did not depend on these initial values. To evaluate the model efficiency, the determination coefficient, $R^{2}$, was calculated for each experimental curve, leading to three coefficients for each muscle.

Since the constitutive laws employed are nonlinear, it is not valid to simply take the mean of the material parameters to obtain parameters describing an average fit. Instead, the parameters defining average fits were determined by the following procedure. Theoretical curves were generated for the same strain and time ranges using the constitutive equations (equation (8)), geometrical characteristics (mean section and length of the 10 specimens), and fitted parameters for each set (for each of the 10 parameter sets corresponding to each subject and for each velocity). These curves could then be used to define a single average curve for each velocity: three curves were obtained. Then, the mean parameters

Table I. Geometrical parameters for each tested muscle.

\begin{tabular}{lll}
\hline Muscle & $I(\mathrm{~mm})$ & $\mathrm{S}\left(\mathrm{mm}^{2}\right)$ \\
\hline Subject I left & 218 & 74 \\
Subject I right & 236 & 73 \\
Subject 2 left & 242 & 129 \\
Subject 2 right & 224 & 270 \\
Subject 3 left & 203 & 77 \\
Subject 3 right & 207 & 87 \\
Subject 4 left & 221 & 244 \\
Subject 4 right & 184 & 175 \\
Subject 5 left & 264 & 213 \\
Subject 5 right & 277 & 185 \\
Mean & 228 & 153 \\
SD & 28 & 75 \\
Minimum & 184 & 73 \\
Maximum & 277 & 270 \\
\hline
\end{tabular}

SD: standard deviation.

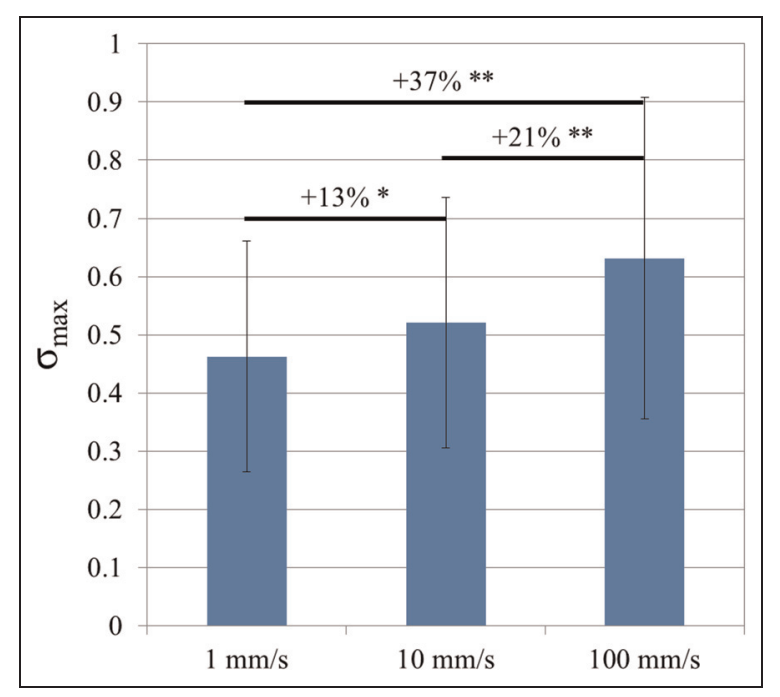

Figure 5. Statistical results for the maximum stress. The mean value and standard deviation are plotted. Differences between mean values at each velocity are given in percentage when there is a significant effect of velocity $(n=10)$.

${ }^{*} p<0.02, * * p<0.01$.

were obtained by fitting the model on the three average engineering stress-engineering strain curves.

\section{Results}

Geometrical parameters were similar for all the muscles (Table 1). The mean initial length after the pre-load was $228 \mathrm{~mm}$ (standard deviation (SD): $28 \mathrm{~mm}$ ), and the mean cross-sectional area was $153 \mathrm{~mm}^{2}$ (SD: $75 \mathrm{~mm}^{2}$ ). The engineering stress-engineering strain experimental curves presented the same shape for all the muscles (Figure 5). Inter- and intra-individual variabilities were observed, as well as an effect of velocity on the response. An increase in velocity led to an increase in the maximum stress measured. The average maximum stress was $0.46 \mathrm{MPa}$ for $1 \mathrm{~mm} \mathrm{~s}^{-1}, 0.52 \mathrm{MPa}$ for $10 \mathrm{~mm} \mathrm{~s}^{-1}$, and $0.63 \mathrm{MPa}$ for $100 \mathrm{~mm} \mathrm{~s}^{-1}$ (Figure 5). This result was confirmed by the statistical analysis. It showed that the maximum stress was sensitive to velocity changes (Figure 5). All the changes in velocity affected the maximum stress with an increase ranging from $13 \%$ to $37 \%$. Therefore, the need for a nonlinear viscoelastic model was justified.

The strain and strain rates applied to the muscles changed because of the muscles' length. The maximum strain was between $2.9 \%$ and $4.3 \%$, with a mean value of $3.6 \%$. The average strain rate was $0.0045 \mathrm{~s}^{-1}$ (SD: $0.0005 \mathrm{~s}^{-1}$, minimum: $0.0036 \mathrm{~s}^{-1}$, maximum: $0.0054 \mathrm{~s}^{-1}$ ) for $1 \mathrm{~mm} \mathrm{~s}^{-1}, 0.045 \mathrm{~s}^{-1}$ (SD: $0.005 \mathrm{~s}^{-1}$ ) for $10 \mathrm{~mm} \mathrm{~s}^{-1}$, and $0.45 \mathrm{~s}^{-1}$ (SD: $0.05 \mathrm{~s}^{-1}$ ) for $100 \mathrm{~mm} \mathrm{~s}^{-1}$.

The parameters of the nonlinear model at the firstand second-order are presented in Tables 2 and 3. They reflect the inter- and intra-individual variabilities of the results. The results also present high similarity. The results for the second-order model are almost exactly 
the same as for the first-order model. The relaxation times are the same and the sum of viscosity parameters in the second-order model equals the viscosity parameter of the first-order model. Therefore, a first-order model is enough to characterize the muscles response. The nonlinear viscoelastic models properly described the experimental curves. The mean determination coefficient $R^{2}$ was 0.98 (minimum: 0.95, maximum: 1.00) for all the muscles tested at $1 \mathrm{~mm} \mathrm{~s}^{-1}$, it was 0.99 (minimum: 0.98, maximum: 1.00 ) at $10 \mathrm{~mm} \mathrm{~s}^{-1}$, and it was 1.00 (minimum: 0.99, maximum: 1.00) at $100 \mathrm{~mm} \mathrm{~s}^{-1}$. An example of the first-order model response is shown in Figure 6.

\section{Discussion}

The passive properties of postmortem human muscle tissue were studied using a simple nonlinear viscoelastic model. Tensile tests at various velocities were performed on 10 extensor carpi ulnaris muscles in vitro. The parameters of the model were identified using a nonlinear least-square method.
The tested muscles were obtained from aged males. These age group and gender features have an effect on the results presented in this article. Mechanical parameters of the model would probably have been different if muscles from a younger population or female subjects have been chosen. To be able to draw more general conclusions on the muscle mechanical properties, further experiments on a larger population are required.

The muscles were collected from human cadavers that were frozen at $-20{ }^{\circ} \mathrm{C}$ post rigor mortis and then slowly thawed at $4{ }^{\circ} \mathrm{C}$. Rigor mortis has an effect on muscle mechanical properties. ${ }^{17,38,40}$ Indeed, muscle stiffness increases significantly a few hours after death, when rigor mortis onsets. ${ }^{17}$ Nevertheless, as highlighted by Van Ee et al., ${ }^{38}$ the Young's modulus of muscles tested post rigor mortis was not statistically different from the Young's modulus of muscles tested before appearance of rigor mortis. However, the no-load region was larger for preconditioned muscles tested post rigor mortis compared to the ones tested before appearance of rigor mortis, leading to a less stiff response. Therefore, we can assume that the

Table 2. Parameters of the first-order Maxwell model for each tested muscle.

\begin{tabular}{llllll}
\hline Muscle & $E(\mathrm{MPa})$ & $\alpha$ & $\eta(\mathrm{MPas})$ & $\tau(\mathrm{s})$ & $E_{M}(\mathrm{MPa})$ \\
\hline Subject I left & 9.4 & 28.5 & 1.8 & 0.30 & 6.0 \\
Subject I right & 12.0 & 25.8 & 1.2 & 0.11 & 10.4 \\
Subject 2 left & 7.9 & 37.4 & 3.0 & 0.29 & 10.3 \\
Subject 2 right & 3.7 & 30.7 & 0.2 & 0.14 & 1.5 \\
Subject 3 left & 8.9 & 28.1 & 1.9 & 0.34 & 5.6 \\
Subject 3 right & 9.3 & 26.4 & 1.0 & 0.25 & 4.1 \\
Subject 4 left & 3.5 & 33.7 & 1.1 & 0.43 & 2.6 \\
Subject 4 right & 3.3 & 28.9 & 0.4 & 0.09 & 3.9 \\
Subject 5 left & 4.5 & 39.5 & 1.0 & 0.46 & 2.1 \\
Subject 5 right & 5.6 & 44.6 & 3.0 & 1.33 & 2.3 \\
Mean & 6.8 & 31.6 & 1.2 & 0.25 & 4.7 \\
Minimum & 3.3 & 25.8 & 0.2 & 0.09 & 1.5 \\
Maximum & 12.0 & 44.6 & 3.0 & 1.33 & 10.4 \\
\hline
\end{tabular}

Mean values of the parameters were obtained as described in section "Materials and methods."

Table 3. Parameters of the second-order Maxwell model for each tested muscle.

\begin{tabular}{llllllllll}
\hline Muscle & $E(\mathrm{MPa})$ & $\alpha$ & $\eta_{1}(\mathrm{MPa} \mathrm{s})$ & $\tau_{1}(\mathrm{~s})$ & $E_{M 1}(\mathrm{MPa})$ & $\eta_{2}(\mathrm{MPa} \mathrm{s})$ & $\tau_{2}(\mathrm{~s})$ & $E_{M 2}(\mathrm{MPa})$ & $E_{M}(\mathrm{MPa})$ \\
\hline Subject I left & 9.4 & 28.6 & 0.92 & 0.31 & 3.0 & 0.92 & 0.31 & 3.0 & 6.0 \\
Subject I right & 12.0 & 25.7 & 0.59 & 0.11 & 5.2 & 0.59 & 0.11 & 5.2 & 10.4 \\
Subject 2 left & 7.9 & 37.4 & 1.41 & 0.29 & 4.8 & 1.60 & 0.29 & 5.5 & 10.3 \\
Subject 2 right & 3.7 & 30.7 & 0.10 & 0.14 & 0.7 & 0.10 & 0.14 & 0.7 & 1.5 \\
Subject 3 left & 8.9 & 28.1 & 0.95 & 0.34 & 2.8 & 0.95 & 0.34 & 2.8 & 5.6 \\
Subject 3 right & 9.3 & 26.4 & 0.47 & 0.25 & 1.9 & 0.54 & 0.25 & 2.1 & 4.1 \\
Subject 4 left & 3.5 & 33.7 & 0.57 & 0.43 & 1.3 & 0.57 & 0.43 & 1.3 & 2.6 \\
Subject 4 right & 3.3 & 28.9 & 0.18 & 0.09 & 1.9 & 0.18 & 0.09 & 1.9 & 3.9 \\
Subject 5 left & 4.5 & 39.5 & 0.49 & 0.46 & 1.1 & 0.49 & 0.46 & 1.1 & 2.1 \\
Subject 5 right & 5.8 & 43.7 & 1.09 & 1.00 & 1.1 & 1.09 & 1.00 & 1.1 & 2.2 \\
Mean & 6.8 & 31.7 & 0.98 & 0.44 & 2.2 & 0.37 & 0.14 & 2.6 & 4.8 \\
Minimum & 3.3 & 25.7 & 0.10 & 0.09 & 0.7 & 0.10 & 0.09 & 0.7 & 1.5 \\
Maximum & 12.0 & 43.7 & 1.41 & 1.00 & 5.2 & 1.60 & 1.00 & 5.5 & 10.4 \\
\hline
\end{tabular}

Mean values of the parameters were obtained as described in section "Materials and methods." 


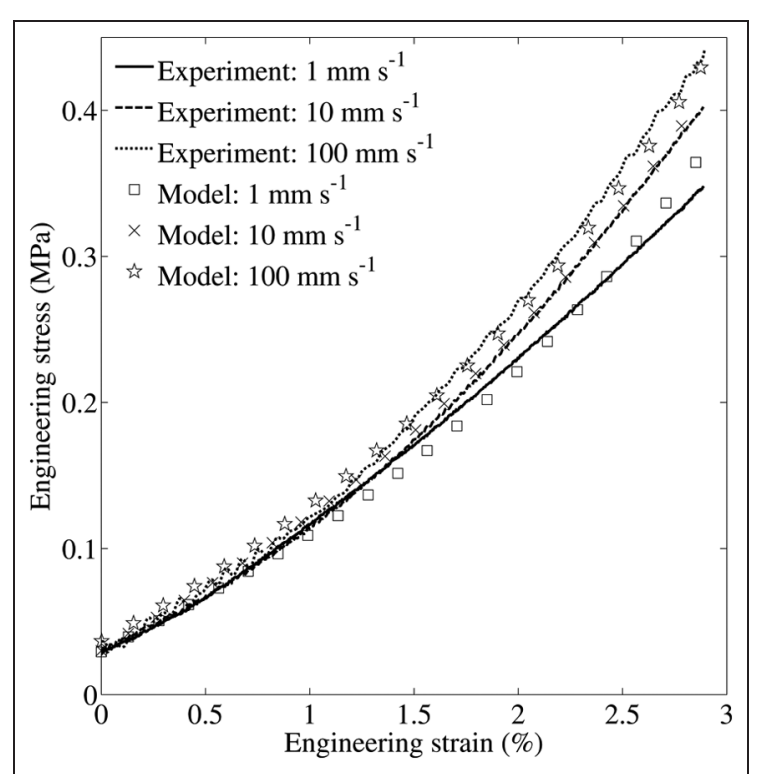

Figure 6. Example of model fitting with experimental curves. The engineering stress-engineering strain curves obtained for one muscle at each velocity are compared with the results obtained with the nonlinear viscoelastic model.

mechanical properties of the muscles in this study were not affected by rigor mortis. However, these results were obtained for animal tissue and may differ from human tissue. The differences between the response of aged and fresh human tissue and between fresh human tissue and fresh animal tissue are unknown. Moreover, there is no evidence that viscoelastic properties are affected or not by rigor mortis. These points should be further investigated.

After collection, the muscles were preserved at $-20{ }^{\circ} \mathrm{C}$ until testing. Cryopreservation is known to alter the mechanical properties of soft tissues such as muscle. According to Ralis, ${ }^{41}$ ice crystals are formed within the tissue at temperatures between $-15^{\circ} \mathrm{C}$ and $-60{ }^{\circ} \mathrm{C}$, which damage the fibers of muscles. This was confirmed by Gottsauner-Wolf et al. ${ }^{23}$ by histological analysis that highlighted the presence of lesions within the tissue. However, Van Ee et al. ${ }^{38}$ showed that the post rigor freeze-thaw cycle was not found to affect the strain-stress response of muscle, and that if the mechanical properties were stabilized ahead of the test, measurements were repeatable, but would underestimate the response of a fresh muscle, or a live muscle. Consequently, experimental results are modified by this conservative method and must be interpreted with caution. To the best of the authors' knowledge, the effects of freeze-thaw process on the viscoelastic properties of muscle tissue are unknown.

Regarding the strain, an elongation of $8 \mathrm{~mm}$ was applied to the whole structure, which represents a mean strain of $3.6 \%$ (SD: $0.5 \%$ ). This value is in the range of what was obtained in the simulations, but it is low compared to strains observed in the literature. For instance, Best et al. ${ }^{37}$ applied a strain of up to $12 \%$ on rabbit muscles, and Bensamoun et al. ${ }^{42}$ applied 20\% strain on rat muscles in tension. In Gras et al., ${ }^{32,33}$ the strain applied to the human sternocleidomastoideus muscle reached $14 \%$. However, the experimental protocols proposed in these studies differ from the one used with the extensor carpi ulnaris muscle, especially regarding the initial state. In Gras et al., ${ }^{32,33}$ the preload applied to the muscle is $2 \mathrm{~N}$, whereas it is $5 \mathrm{~N}$ in this study. This affects the tension in the muscle fibers and thus the strain that fibers can reach thereafter; muscle fibers were probably not only straighten but already stretched. ${ }^{29}$ The extensor carpi ulnaris muscle is also a pinnate muscle, and therefore, the muscle fibers are smaller than in a fusiform muscle with parallel fibers; there is more connective tissue in the muscle and the tendons are inserted deeply in the muscle belly. Consequently, muscle stretching is more limited. Moreover, in preliminary tests, rupture of the muscle was observed when the applied displacement exceeded $10 \mathrm{~mm}$. This explains the low strain which is relative, since the length of the muscle in situ was unknown.

The velocities applied to the muscles $(1,10$, and $100 \mathrm{~mm} \mathrm{~s}^{-1}$ ) correspond, respectively, to the following strain rates: $0.0045,0.045$, and $0.45 \mathrm{~s}^{-1}$. The strain rates, as well as the strain applied to the muscles, were thus representative of what would have been experienced in a low severity impact. For general impact, higher strain and strain rates should be evaluated; however, the studied strain rates are still useful, for instance, for the development of pre-crash human body numerical models ${ }^{8}$ where loadings are lower than in crash situations and where muscles are modeled with 1D elements.

In the literature, Best et al. ${ }^{37}$ used strain rates ranging from 0.01 to $2 \mathrm{~s}^{-1}$ to demonstrate the sensitivity to strain rate of rabbit muscles in tension. Taylor et al. ${ }^{43}$ studied the viscoelastic response of rabbit muscletendon units. They were submitted to stretch ramps performed at $0.1,1,10$, and $100 \mathrm{~mm} \mathrm{~s}^{-1}$; yet the corresponding strain rates were not indicated. The tensile tests performed by Myers et al. ${ }^{25,26}$ on rabbit muscles were at strain rates of 1,10 , and $25 \mathrm{~s}^{-1}$. Noonan et al. ${ }^{27,28}$ evaluated the effect of two velocities, 10 and $100 \mathrm{~mm} \mathrm{~s}^{-1}$, that corresponded to 0.1 and $1 \mathrm{~s}^{-1}$, on various parameters such as stiffness on rabbit muscles. In our study, even though the strain rates were lower than in Myers et al., ${ }^{25,26}$ they were sufficiently different to highlight their effect on the muscle response, and thus to allow the identification of the viscoelastic parameters of the model.

Only the muscle initial length and cross-sectional area were used to assess the mechanical parameters of the model. They presented intra- and mostly interindividual variabilities, especially the cross-sectional area. The entire geometry of the muscles has not been assessed in this study. If it would have been the case, subject-specific finite element models of each muscle could have been created to determine their mechanical properties with an inverse method. This could have 
been helpful to identify the stress and strain distributions within the muscle; however, the goal of the study was only to obtain apparent mechanical properties of a human muscle that could be used for the definition of 1D muscles in numerical models. Therefore, only basic geometrical features were required to characterize the muscle response. ${ }^{32}$ In future work, these basic geometrical features could be easily derived from 3D geometry recorded, for instance, by a laser scanner.

The proposed nonlinear viscoelastic model is simple. Only four to six parameters are required to describe the response of the muscle in tension. The model is valid in this case for small strain values, but its ability to model muscle response at strain up to $14 \%$ has been previously showed. ${ }^{32,33}$ The hyper-elastic response described with an exponential law has been used to characterize the passive response of other human muscle in tension at a low strain rate. ${ }^{32,33}$ Regarding the viscoelastic behavior, a first- and second-order Maxwell model was chosen. ${ }^{13,21,33,43,44}$ In Gras et al., ${ }^{33}$ the second-order model gave better results than the first-order model; in this study, both models gave the same results. The second-order model allows a wider range of mechanical response.

The parameters identified with the model are specific to the extensor carpi ulnaris muscle of the selected age group and gender and for the specific experimental conditions including velocities and pre-load. The model's parameters were identified using three experimental curves. Another test may be useful to obtain a more precise estimate of the parameters. However, Taylor et al. ${ }^{43}$ recommended no more than four tests on a same muscle, because of observed alteration of the muscle tissue thereafter. To ensure the measured response was not altered, we decided to test only three velocities.

The parameters are in the same order of magnitude as those reported in the literature; however, they are higher, in particular the Young's modulus E. The Young's modulus $E$ in our study is in mean $6.8 \mathrm{MPa}$, whereas it was $2 \mathrm{MPa}$ for a dog muscle in compres$\operatorname{sion}^{15}$ or a rabbit muscle in tension at $20 \%$ strain. $^{26}$ For a lower limb finite element model, Behr et al. ${ }^{1}$ used a Young's modulus of $1 \mathrm{MPa}$ in the tension direction and $5 \mathrm{MPa}$ in the direction perpendicular to the tension direction. Gras et al. ${ }^{32}$ identified a Young's modulus of $0.1 \mathrm{MPa}$ for the human sternocleidomastoideus muscle. Bosboom et al. ${ }^{13}$ used the Ogden's law to characterize the response of a rat muscle in compression; the equivalent Young's modulus was 0.05 MPa. An explanation for the high value of our Young's modulus is the fact that the extensor carpi ulnaris muscle is a pinnate muscle with a deep insertion of the tendons in the muscle belly. Hence, it presents a larger amount of connective tissue than a fusiform muscle such as the sternocleidomastoideus muscle, for instance. This modulus is an apparent modulus for the muscle structure. In addition, the initial state of the muscle affects the mechanical response as mentioned previously. Moreover, the calculation of the Young's modulus is based on the calculated engineering stress. This stress depends on the cross-sectional area. This area was preferred over physiological cross-sectional area because muscle was elongated in its longitudinal direction, and not in the fiber direction. To improve the experimental protocol, medical imaging should be considered in order to obtain the physiological cross-sectional area.

The curvature parameter $\alpha$ was 31.6 in this study. For the sternocleidomastoideus muscle tested in tension, it was $24,{ }^{32,33}$ and for a rat muscle in compression it was $21 .^{13}$ Regarding the viscoelastic parameters $\eta$ and $\tau$, a comparison with the literature was not possible, because no comparable data were found.

Comparison with the literature is also limited, because very few experiments have been performed on human muscles. ${ }^{14,31-34}$ Moreover, as highlighted by Yamada ${ }^{34}$ high variability exists in the response of different human muscles. For instance, Gras et al. ${ }^{32,33}$ measured a stress of $0.01 \mathrm{MPa}$ at $5 \%$ strain for the sternocleidomastoideus muscle and at a strain rate of $0.001 \mathrm{~s}^{-1}$; whereas in this work, at $3.6 \%$ strain and at the lowest strain rate $\left(0.0045 \mathrm{~s}^{-1}\right)$ the average stress was $0.46 \mathrm{MPa}$ for the extensor carpi ulnaris muscle. Even though the experimental protocol differs slightly from one experiment to the other and the physiological cross-sectional area is not considered to calculate the stress, there is a factor of 50 between the engineering stress measurements at the same strain for these two muscles. These values represent apparent properties of the muscle structure, including the muscle belly and connective tissue.

In conclusion, this work provides new knowledge of the passive mechanical behavior of human muscles in tension that could be useful in the field of impact biomechanics, as well as in biomechanics in general. It proposes a simple nonlinear viscoelastic model considering basic geometrical features to describe the passive response of muscles in tension. The results could be used in the definition of $1 \mathrm{D}$ muscles in human body numerical models developed to reproduce pre-crash events. However, it should be noted that these results are obtained for one specific muscle. Indeed, the results suggest the use of specific passive properties for different groups of muscles in human body models. Therefore, the approach proposed in this study could be reproduced to characterize other human muscles.

\section{Acknowledgements}

The authors would like to thank Yann Le Corvec for his technical support in the setting of the protocol. The authors are grateful to Dr Anthony Viste and Dr Frédéric Rongieras for muscle dissection.

\section{Declaration of conflicting interests}

None of the authors have any conflicts of interest to report. 


\section{Funding}

This work was supported by the GDR 2610 "Biomécanique des chocs" (CNRS/INRETS/GIE PSA Renault).

\section{References}

1. Behr M, Arnoux PJ, Serre T, et al. Tonic finite element model of the lower limb. J Biomech Eng 2006; 128: 223228.

2. Frechede B, Bertholon N, Lecoz J, et al. Finite element model of the human neck during omni-directional impacts. Part I. Kinematics and injury. Eur J Comput Mech 2005; 14: 463-485.

3. Frechede B, Bertholon N, Saillant G, et al. Finite element model of the human neck during omni-directional impacts. Part II. Relation between cervical curvature and risk of injury. Comput Meth Biomech Biomed Eng 2006; 9: 379-386.

4. Hedenstierna S, Halldin P and Brolin K. Evaluation of a combination of continuum and truss finite elements in a model of passive and active muscle tissue. Comput Meth Biomech Biomed Eng 2008; 11: 627-639.

5. Brolin K, Halldin P and Leijonhufvud I. The effect of muscle activation on neck response. Traffic Inj Prev 2005; 6: 67-76.

6. Fice JB and Cronin DS. Investigation of whiplash injuries in the upper cervical spine using a detailed neck model. J Biomech 2012; 45: 1098-1102.

7. Meijer R, Rodarius C, Adamec J, et al. A first step in computer modelling of the active human response in a far-side impact. Int J Crashworthines 2008; 13: 643-652.

8. Östh J, Brolin K, Carlsson S, et al. The occupant response to autonomous braking: a modeling approach that accounts for active musculature. Traffic Inj Prev 2012; 13: 265-277.

9. Panzer MB, Fice JB and Cronin DS. Cervical spine response in frontal crash. Med Eng Phys 2011; 33: 11471159.

10. Soni A, Chawla A and Mukherjee S. Response of tonic lower limb FE model in various real life car-pedestrian impact configurations: a parametric study for standing posture. Int J Veh Saf 2009; 4: 14-28.

11. Stemper BD, Yoganandan N and Pintar FA. Validation of a head-neck computer model for whiplash simulation. Med Biol Eng Comput 2004; 42: 333-338.

12. Aimedieu P, Mitton D, Faure JP, et al. Dynamic stiffness and damping of porcine muscle specimens. Med Eng Phys 2003; 25: 795-799.

13. Bosboom EM, Hesselink MK, Oomens CW, et al. Passive transverse mechanical properties of skeletal muscle under in vivo compression. $J$ Biomech 2001; 34: 1365-1368.

14. Chawla A, Mukherjee S and Karthikeyan B. Characterization of human passive muscles for impact loads using genetic algorithm and inverse finite element methods. Biomech Model Mechanobiol 2009; 8: 67-76.

15. Gras LL, Mitton D, Crevier-Denoix N, et al. The nonlinear response of a muscle in transverse compression: assessment of geometry influence using a finite element model. Comput Meth Biomech Biomed Eng 2012; 15: 13-21.

16. Takaza M and Simms CK. The passive response of skeletal muscle to compressive impact loading. In: IRCOBI conference, Dublin, 12-14 September 2012, paper no. IRC-12-60, pp.503-514, available at http://ircobi.org/ downloads/irc12/pdf_files/60.pdf.

17. Van Loocke M, Lyons CG and Simms CK. A validated model of passive muscle in compression. $J$ Biomech 2006; 39: 2999-3009.

18. Van Loocke M, Lyons CG and Simms CK. Viscoelastic properties of passive skeletal muscle in compression: stress-relaxation behaviour and constitutive modelling. $J$ Biomech 2008; 41: 1555-1566.

19. Van Loocke M, Simms CK and Lyons CG. Viscoelastic properties of passive skeletal muscle in compression-cyclic behaviour. J Biomech 2009; 42: 1038-1048.

20. Anderson J, Li Z and Goubel F. Models of skeletal muscle to explain the increase in passive stiffness in desmin knockout muscle. J Biomech 2002; 35: 1315-1324.

21. Anderson $\mathrm{J}, \mathrm{Li} \mathrm{Z}$ and Goubel F. Passive stiffness is increased in soleus muscle of desmin knockout mouse. Muscle Nerve 2001; 24: 1090-1092.

22. Davis J, Kaufman KR and Lieber RL. Correlation between active and passive isometric force and intramuscular pressure in the isolated rabbit tibialis anterior muscle. J Biomech 2003; 36: 505-512.

23. Gottsauner-Wolf F, Grabowski JJ, Chao EY, et al. Effects of freeze/thaw conditioning on the tensile properties and failure mode of bone-muscle-bone units: a biomechanical and histological study in dogs. J Orthopaed Res 1995; 13: 90-95.

24. Lin R, Chang G and Chang L. Biomechanical properties of muscle-tendon unit under high-speed passive stretch. Clin Biomech 1999; 14: 412-417.

25. Myers BS, Van Ee CA, Camacho DLA, et al. On the structural and material properties of mammalian skeletal muscle and its relevance to human cervical impact dynamics. Stapp Car Crash J 1995; 39: 203-214.

26. Myers BS, Woolley CT, Slotter TL, et al. The influence of strain rate on the passive and stimulated engineering stress - large strain behavior of the rabbit tibialis anterior muscle. J Biomech Eng 1998; 120: 126-132.

27. Noonan TJ, Best TM, Seaber AV, et al. Identification of a threshold for skeletal muscle injury. Am J Sport Med 1994; 22: 257-261.

28. Noonan TJ, Best TM, Seaber AV, et al. Thermal effects on skeletal muscle tensile behavior. Am J Sport Med 1993; 21: 517-522.

29. Takaza M, Moerman KM, Gindre J, et al. The anisotropic mechanical behaviour of passive skeletal muscle tissue subjected to large tensile strain. J Mech Behav Biomed Mater 2013; 17: 209-220.

30. Dhaliwal TS, Beillas P, Chou CC, et al. Structural response of lower leg muscles in compression: a low impact energy study employing volunteers, cadavers and the Hybrid III. Stapp Car Crash J 2002; 46: 229-243.

31. Untaroiu C, Darvish K, Crandall J, et al. Characterization of the lower limb soft tissues in pedestrian finiteelement models. In: Proceedings of the 19th international technical conference on the enhanced safety of vehicles, Washington DC, 6-9 June 2005, available at http://www .nrd.nhtsa.dot.gov/pdf/ESV/esv19/05-0250-O.pdf.

32. Gras LL, Mitton D, Viot P, et al. Hyper-elastic properties of the human sternocleidomastoideus muscle in tension. $J$ Mech Behav Biomed Mater 2012; 15: 131-140.

33. Gras LL, Mitton D, Viot P, et al. Viscoelastic properties of the human sternocleidomastoideus muscle of aged 
women in relaxation. $J$ Mech Behav Biomed Mater 2013; 27: 77-83.

34. Yamada H. Strength of biological materials. Baltimore, MD: The Williams \& Wilkins Company, 1970.

35. Mutungi $\mathrm{G}$ and Ranatunga KW. The viscous, viscoelastic and elastic characteristics of resting fast and slow mammalian (rat) muscle fibres. J Appl Physiol 1996; 496: 827836.

36. Lieber RL, Runesson E, Einarsson F, et al. Inferior mechanical properties of spastic muscle bundles due to hypertrophic but compromised extracellular matrix material. Muscle Nerve 2003; 28(4): 464-471.

37. Best TM, McElhaney J, Garrett WE, et al. Characterization of the passive responses of live skeletal muscle using the quasi-linear theory of viscoelasticity. J Biomech 1994; 27: 413-419.

38. Van Ee CA, Chasse AL and Myers BS. Quantifying skeletal muscle properties in cadaveric test specimens: effects of mechanical loading, postmortem time, and freezer storage. J Biomech Eng 2000; 122: 9-14.
39. Sten-Knudsen O. Torsional elasticity of the isolated cross striated muscle fibre. Acta Physiol Scand 1953; 28(Suppl. 104): 1-240.

40. Kobayashi M, Takatori T, Iwadate K, et al. Reconsideration of the sequence of rigor mortis through postmortem changes in adenosine nucleotides and lactic acid in different rat muscles. Forensic Sci Int 1996; 82: 243-253.

41. Ralis ZA. Freezing of orthopaedic specimens before mechanical testing. J Bone Joint Surg Br 1989; 71: 55-57.

42. Bensamoun S, Stevens L, Fleury MJ, et al. Macroscopicmicroscopic characterization of the passive mechanical properties in rat soleus muscle. $J$ Biomech 2006; 39: 568-578.

43. Taylor DC, Dalton J Jr, Seaber AV, et al. Viscoelastic properties of muscle-tendon units. The biomechanical effects of stretching. Am J Sport Med 1990; 18: 300-309.

44. Ito D, Tanaka $\mathrm{E}$ and Yamamoto $\mathrm{S}$. A novel constitutive model of skeletal muscle taking into account anisotropic damage. J Mech Behav Biomed Mater 2010; 3: 85-93. 